Article

\title{
Diagnostic and Prognostic Value of a TDI-Derived Systolic Wall Motion Analysis as a Screening Modality for Allograft Rejection after Heart Transplantation
}

\author{
Isabell A. Just 1,2,*(D), Meryem Guelfirat ${ }^{1}$, Laura Leser ${ }^{3}$, Ata Uecertas ${ }^{1}$, Laurenz Kopp Fernandes ${ }^{1}$, Maren Godde ${ }^{1}$, \\ Nicolas Merke ${ }^{1}$, Philipp Stawowy ${ }^{2,4}$, Felix Hennig ${ }^{1,2}$, Christoph Knosalla 1,2 $\mathbb{D}$, Volkmar Falk 1,2,5,6, \\ Jan Knierim ${ }^{1,+} \mathbb{D}$ and Felix Schoenrath $1,2,+\mathbb{D}$
}

check for updates

Citation: Just, I.A.; Guelfirat, M.;

Leser, L.; Uecertas, A.;

Kopp Fernandes, L.; Godde, M.; Merke, N.; Stawowy, P.; Hennig, F.; Knosalla, C.; et al. Diagnostic and Prognostic Value of a TDI-Derived Systolic Wall Motion Analysis as a Screening Modality for Allograft Rejection after Heart Transplantation. Life 2021, 11, 1206. https:/ / doi.org/ 10.3390/life11111206

Academic Editors: Rasmus Rivinius and Andreas Doesch

Received: 21 October 2021

Accepted: 7 November 2021

Published: 9 November 2021

Publisher's Note: MDPI stays neutral with regard to jurisdictional claims in published maps and institutional affiliations.
1 Department of Cardiothoracic and Vascular Surgery, German Heart Center Berlin, 13353 Berlin, Germany; meryemguelfirat@gmail.com (M.G.); uecertas@dhzb.de (A.U.); kopp@dhzb.de (L.K.F.); godde@dhzb.de (M.G.); merke@dhzb.de (N.M.); hennig@dhzb.de (F.H.); knosalla@dhzb.de (C.K.); falk@dhzb.de (V.F.); knierim@dhzb.de (J.K.); schoenrath@dhzb.de (F.S.)

2 DZHK (German Centre for Cardiovascular Research), Partner Site Berlin, 10785 Berlin, Germany; stawowy@dhzb.de

3 Department of Anesthesiology, German Heart Center Berlin, 13353 Berlin, Germany; leser@dhzb.de

4 Department of Cardiology and Internal Medicine, German Heart Center Berlin, 13353 Berlin, Germany

5 Department of Cardiothorarcic Surgery, Charité, Corpoate Member of Freie Universität Berlin, Humboldt-Universitüt Berlin and Berlin Institute of Health, 13353 Berlin, Germany

6 Translational Cardiovascular Technologies, Department of Health Sciences, Eidgenoessische Technische Hochschule (ETH) Zurich, 8092 Zurich, Switzerland

* Correspondence: ijus@@dhzb.de

+ These authors contributed equally to this work.

\begin{abstract}
Background: Despite the risk for complications, allograft surveillance after orthotopic heart transplantation $(\mathrm{OHT})$ is performed by cardiac catheterization and biopsies. We investigated the diagnostic and prognostic value of a TDI-derived systolic wall motion analysis of the posterobasal wall of the left ventricle $(\mathrm{Sm})$ as a screening modality in OHT aftercare. Methods: We examined data of 210 eligible patients who underwent OHT between 2010 and 2020. Forty-four patients who had died within the initial hospital stay were excluded. For 166 patients, baseline and follow-up data were analyzed. The mean age at OHT was $46.2( \pm 11.4)$ years; $76.5 \%$ were male. Results: Within the observational period, 22 (13.3\%) patients died. In total, 170 episodes of acute cellular or humoral rejections occurred (84 ISHLT1R; 13 ISHLT2R; 8 ISHLT3R; 65 AMR), and 29 catheterizations revealed cardiac allograft vasculopathy (5 CAV1; 4 CAV2; 20 CAV3). Individual Sm radial/longitudinal remained stable within the follow-up period $(11.5 \pm 2.2 \mathrm{~cm} / \mathrm{s} ; 10.9 \pm 2.1 \mathrm{~cm} / \mathrm{s})$. Patients with acute rejections and CAV3 showed significant $S m$ radial/longitudinal reductions (AMR1: $1.6 \pm 1.9 \mathrm{~cm} / \mathrm{s}$, confidence interval (CI) 0.77-0.243, $p<0.001 ; 1.8 \pm 2.0 \mathrm{~cm} / \mathrm{s}, \mathrm{CI} 0.92-0.267, p<0.001$. ISHLT1R: $1.7 \pm 1.8 \mathrm{~cm} / \mathrm{s}$, CI 1.32-2.08, $p<0.001 ; 2.0 \pm 1.6 \mathrm{~cm} / \mathrm{s}$, CI 1.66-2.34, $p<0.001$. CAV3: $1.3 \pm 2.5 \mathrm{~cm} / \mathrm{s}$, CI $0.23-2.43, p<0.017 ; 1.4 \pm 2.8 \mathrm{~cm} / \mathrm{s}$, CI 0.21-2.66, $p<0.021)$. Lower Sm was associated with a threefold increase in all-cause mortality (hazard ratio (HR) 3.24, CI 1.2-8.76, $p=0.020$; HR 2.92, CI 1.19-7.18, $p=0.019)$. Overall, Sm-triggered surveillance led to 0.75 invasive diagnostics per patient post-OHT year. Conclusions: Sm remained stable in the post-OHT course. Reductions indicated ISHLT1R, AMR1 and CAV3 and were associated with higher all-cause mortality. Sm-triggered surveillance may be referred to as a safe, high-yield screening modality in OHT aftercare.
\end{abstract}

Keywords: heart transplantation; rejection; surveillance; echocardiography

\section{Introduction}

Acute rejection (AR) and cardiac allograft vasculopathy (CAV) are leading causes of mortality after orthotopic heart transplantation (OHT) [1]. Approximately one-quarter 
of patients experience at least one AR within the first year; in one-third of patients, CAV occurs within 5 years after OHT [2,3].

The early diagnosis and treatment of these complications are crucial in the followup care of heart transplant recipients. Since the symptoms and clinical signs of AR and CAV are often unspecific and typically occur late, routine surveillance by endomyocardial biopsies $(\mathrm{EMB})$ and angiographies are recommended every six to twelve months if the renal function is not severely impaired [4]. Procedures are accompanied by a risk for acute complications and for the development of tricuspid valve regurgitation after repetitive catheter passages [5]. Furthermore, invasive follow-ups consume hospital resources and are of limited acceptance by the patients, leading caregivers to keep the frequency of invasive diagnostics as low as possible. However, this results in a period of uncertainty between examinations, which might be particularly challenging in patients with persisting donorspecific human leukocyte antigene (HLA) antibodies or false negative EMB. Furthermore, routine surveillances of asymptomatic patients may reveal clinically insignificant, lowgrade rejections, and lead to immunosuppressant overtreatment with a concomitant risk for infections and malignancies [6].

Despite advances in noninvasive cardiac imaging, a reliable, easily accessible screening modality for follow-up care after OHT has not yet been widely introduced in clinical practice. In our institution, echocardiographic AR and CAV surveillance via pulsed-wave tissue Doppler imaging (PW-TDI) has been routinely performed and used for navigation of invasive diagnostics for more than 15 years.

The aim of this retrospective analysis was to investigate the long-term course, diagnostic reliability, and prognostic value of systolic wall motion analysis after OHT.

\section{Materials and Methods}

The files of 438 patients who had undergone heart transplantation at our institution between 2006 and 2020 were retrospectively analyzed. Due to technical restrictions of the image data storage before 2010, only patients who had received a transplantation between 2010 and 2020 were further analyzed for eligibility. Recipients aged under 18 years at OHT and patients who had died within the transplant hospital stay were excluded from final analysis (Figure 1).

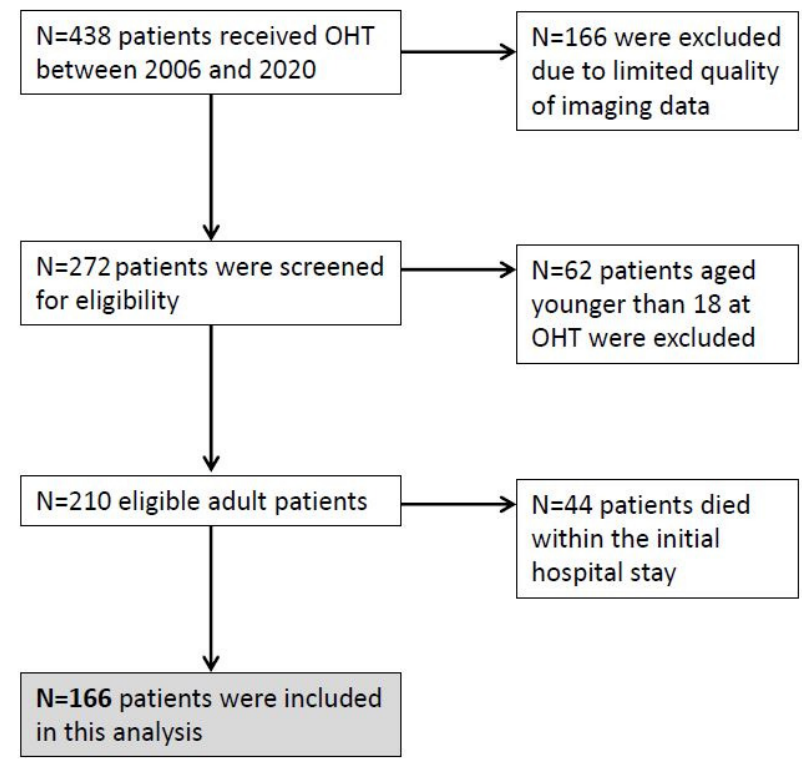

Figure 1. Study cohort.

The baseline characteristics of 166 donors and recipients, including age, sex, body mass index, cause of heart failure, concomitant diseases; intra- and postoperative data, including ischemic time, immunosuppressive treatment, and intensive care unit stay; and 
echocardiographic follow-up data from more than 1100 visits were collected in an electronic database. The study conforms to the principles outlined in the Declaration of Helsinki and was approved by the local ethics committee (EA2/169/19).

AR is referred to as T-cell-mediated acute cellular rejection (ACR), antibody mediated rejection (AMR), or both. AR grading was defined according to the classification of The International Society for Heart and Lung Transplantation (ISHLT) [7,8]. CAV affects both epicardial and intramural coronary arteries, and is characterized by diffuse intimal proliferation with successive lumen narrowing and microvascular dysfunction $[9,10]$. The grading was defined by the degree of stenosis, number and localization of lesions, and graft function, as described by the ISHLT [11].

Systolic wall motion peak velocities (Sm) were measured by PW-TDI at the subendocardial, posterobasal segment of the left ventricle at the level of the mitral leaflet tips. Radial wall motion was measured in parasternal long axis view and longitudinal wall motion in apical 3-chamber view [12]. In routine echocardiography, measurements of the Sm during or after extrasystoles are excluded from analysis. Since transducer angulation might result in a detection of lower velocities, the highest systolic wall motion velocity from at least three beats was selected in clinical routine (Figure 2).
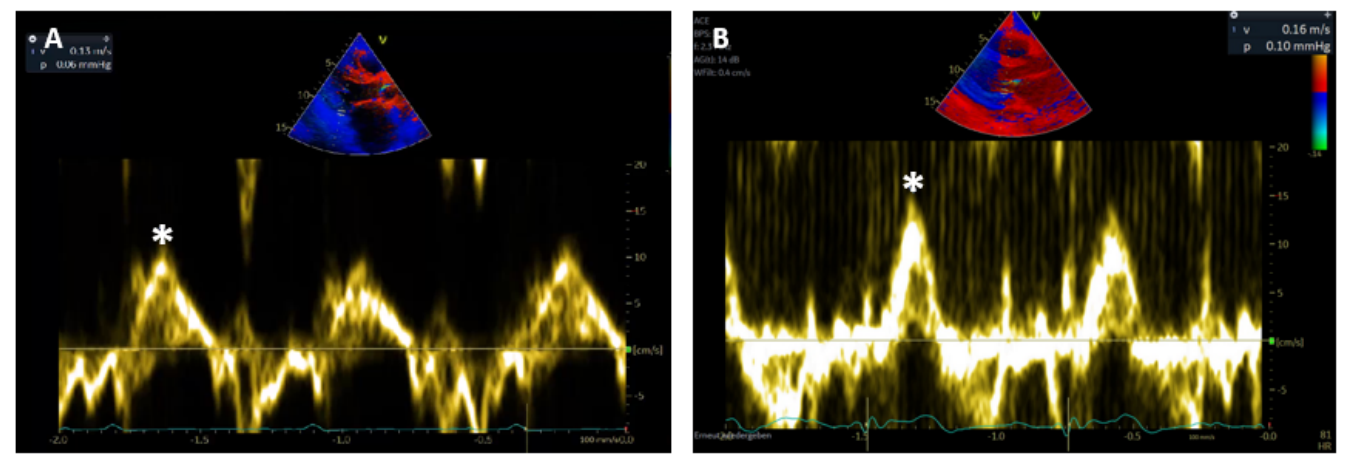

Figure 2. (A) Longitudinal and (B) radial Sm measured by PW-TDI at basal posterolateral segment of the $\operatorname{LV}\left({ }^{*}\right)$.

Clinical, electrocardiographic, and echocardiographic signs of graft failure were routinely evaluated every three to six months in asymptomatic patients in OHT aftercare in our institution. If Sm values decreased by $>10 \%$ compared to individual previous values, invasive diagnostics, including coronary angiography and biopsies, were performed.

Continuous data are summarized as mean and standard deviation (SD) or, in the case of skewed data, as median and interquartile range (IQR). Comparisons between groups were analyzed using t-tests for paired samples. Due to the small samples, $\mathrm{t}$-tests were not calculated for the following groups: Sm reduction in ACR ISHLT $2 \mathrm{R}$ and $3 \mathrm{Rm}$ and ISHLT CAV1 and CAV2. Frequencies and percentages are reported for categorical data. The association of echocardiographic parameters with all-cause mortality was tested in a time-varying covariate Cox regression model. For patients who survived the first year after transplantation, conditional survival rates were analyzed using the Kaplan-Meier method. SPSS 25 and R 4.0 were used for statistical analysis.

\section{Results}

\subsection{Patient Characteristics}

Between 2010 and 2020, 166 adult patients received OHT and survived the transplant hospital stay. The mean age of recipients was $46.2( \pm 11.4)$ years at OHT; donors were aged $40.8( \pm 14.1)$ years. Overall, $127(76.5 \%)$ recipients and 107 (64.5\%) donors were male. Most patients $(88.0 \%)$ underwent heart transplantation in a highly urgent status on the waiting list of Eurotransplant with terminal heart failure, mainly due to dilated cardiomyopathy $(68.7 \%)$ or ischemic heart disease $(21.1 \%)$. Half of the patients $(50.6 \%)$ were on long-term 
mechanical circulatory support before OHT, and three (1.8\%) patients received a combined transplantation of heart and kidney.

Mean ischemic time was 259.9 ( \pm 63.3$)$ minutes. Immunosuppressive therapy included methylprednisolone, calcineurin inhibitors ( $97.4 \%$ cyclosporine, $2.4 \%$ tacrolimus), and antithymocyte globulin $(60.4 \%)$ at induction and methylprednisolone, calcineurin inhibitors (55.4\% cyclosporine, $42.8 \%$ tacrolimus) and mycophenolate mofetil (79.5\%) at discharge. Mean hospital stay was 62.3( \pm 50.7$)$ days (Table 1$)$.

Table 1. Baseline characteristics $n=166$.

\begin{tabular}{|c|c|}
\hline \multicolumn{2}{|c|}{ Recipient } \\
\hline Age at $\mathrm{OHT}$ & $46.2( \pm 11.4)$ \\
\hline Sex (male) & $127(76.5)$ \\
\hline BMI in $\mathrm{kg} / \mathrm{m}^{2}$ & $25.2( \pm 4.0)$ \\
\hline \multicolumn{2}{|l|}{ Waiting list status } \\
\hline Highly urgent & $146(88.0)$ \\
\hline Urgent (until February 2011) & $4(2.4)$ \\
\hline Transplantable & $16(9.6)$ \\
\hline \multicolumn{2}{|l|}{ Diagnosis leading to OHT } \\
\hline DCM & $114(68.7)$ \\
\hline $\mathrm{HCM}$ & $4(2.4)$ \\
\hline $\mathrm{RCM}$ & 0 \\
\hline ARVC & $3(1.8)$ \\
\hline IHD & $35(21.1)$ \\
\hline Other * & $10(6.0)$ \\
\hline Previous VAD & $84(50.6)$ \\
\hline LVAD & $78(47.0)$ \\
\hline RVAD & $1(0.6)$ \\
\hline BVAD & $6(3.6)$ \\
\hline \multicolumn{2}{|l|}{ Concomitant disease } \\
\hline CKD & $115(69.3)$ \\
\hline $\mathrm{DM}$ & $26(15.7)$ \\
\hline Type 1 & $4(2.4)$ \\
\hline Type 2 & $22(13.3)$ \\
\hline HLP & $64(38.6)$ \\
\hline Former smoker & $38(22.9)$ \\
\hline \multicolumn{2}{|c|}{ Donor } \\
\hline Age at donation & $40.8( \pm 14.1)$ \\
\hline Sex (male) & $107(64.5)$ \\
\hline BMI in $\mathrm{kg} / \mathrm{m}^{2}$ & $25.2( \pm 3.7)$ \\
\hline \multicolumn{2}{|l|}{ Echocardiography } \\
\hline LV hypertrophy & $12(7.2)$ \\
\hline \multicolumn{2}{|l|}{ Concomitant disease } \\
\hline Hypertension & $22(13.3)$ \\
\hline
\end{tabular}


Table 1. Cont.

\begin{tabular}{|c|c|}
\hline CAD & $2(1.2)$ \\
\hline $\mathrm{DM}$ & $6(3.6)$ \\
\hline Former smoker & $26(15.7)$ \\
\hline Alcohol abuse & $16(9.6)$ \\
\hline Drug abuse ${ }^{\dagger}$ & $7(4.2)$ \\
\hline Cardiopulmonary resuscitation & $20(12.0)$ \\
\hline \multicolumn{2}{|c|}{ Transplantation } \\
\hline \multicolumn{2}{|l|}{ Combined OHT } \\
\hline Heart-kidney & $3(1.8)$ \\
\hline Ischemic time in $\min$ & $259.9( \pm 63.3)$ \\
\hline ICU stay in days & $26.7( \pm 36.3)$ \\
\hline Hospital stay in days & $62.3( \pm 50.7)$ \\
\hline Inotropic support in days & $8(5-12)$ \\
\hline Mechanical ventilation in days & $5(2-18)$ \\
\hline \multicolumn{2}{|l|}{ GFR at discharge in $\mathrm{ml} / \mathrm{min}$} \\
\hline$>90$ & $67(40.2)$ \\
\hline $60-89$ & $35(21.1)$ \\
\hline $40-59$ & $22(13.3)$ \\
\hline $30-44$ & $19(11.4)$ \\
\hline $15-29$ & $8(4.8)$ \\
\hline RRT & $16(9.6)$ \\
\hline \multicolumn{2}{|l|}{ Immunosuppression induction } \\
\hline Cyclosporine & $162(97.2)$ \\
\hline Tacrolimus & $4(2.4)$ \\
\hline Mycophenolate mofetil & $9(5.4)$ \\
\hline Methylprednisolone & $166(100.0)$ \\
\hline Antithymocyte globulin & $100(60.2)$ \\
\hline Other $\S$ & $4(2.4)$ \\
\hline \multicolumn{2}{|l|}{ Immunosuppression at discharge } \\
\hline Cyclosporine & $92(55.4)$ \\
\hline Tacrolimus & $71(42.8)$ \\
\hline Everolimus & $19(11.4)$ \\
\hline Mycophenolate mofetil & $132(79.5)$ \\
\hline Methylprednisolone & $164(98.8)$ \\
\hline Unknown & $2(1.2)$ \\
\hline
\end{tabular}

ARVC, arrhythmogene right ventricular cardiomyopathy; BMI, body mass index; BVAD, biventricular assist device; CKD, chronic kidney disease; DCM, dilated cardiomyopathy; DM, diabetes mellitus; GFR, glomerular filtration rate; HCM, hypertrophic cardiomyopathy; HLP, hyperlipidemia; ICU, intensive care unit; IHD, ischemic heart disease; LVAD, left ventricular assist device; OHT, orthotopic heart transplantation; RCM, restrictive cardiomyopathy; RRT, renal replacement therapy; RVAD, right ventricular assist device; VAD, ventricular assist device; * others: transposition of the great arteries, noncompaction cardiomyopathy, peripartum cardiomyopathy;

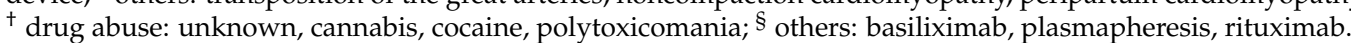




\subsection{Invasive Diagnostics in OHT Follow-Up}

Overall, 480 invasive diagnostics, including 233 EMB, 38 angiographies, and 208 combined procedures, were performed, resulting in 0.75 invasive diagnostics per patient post-transplant year (Figure 3).

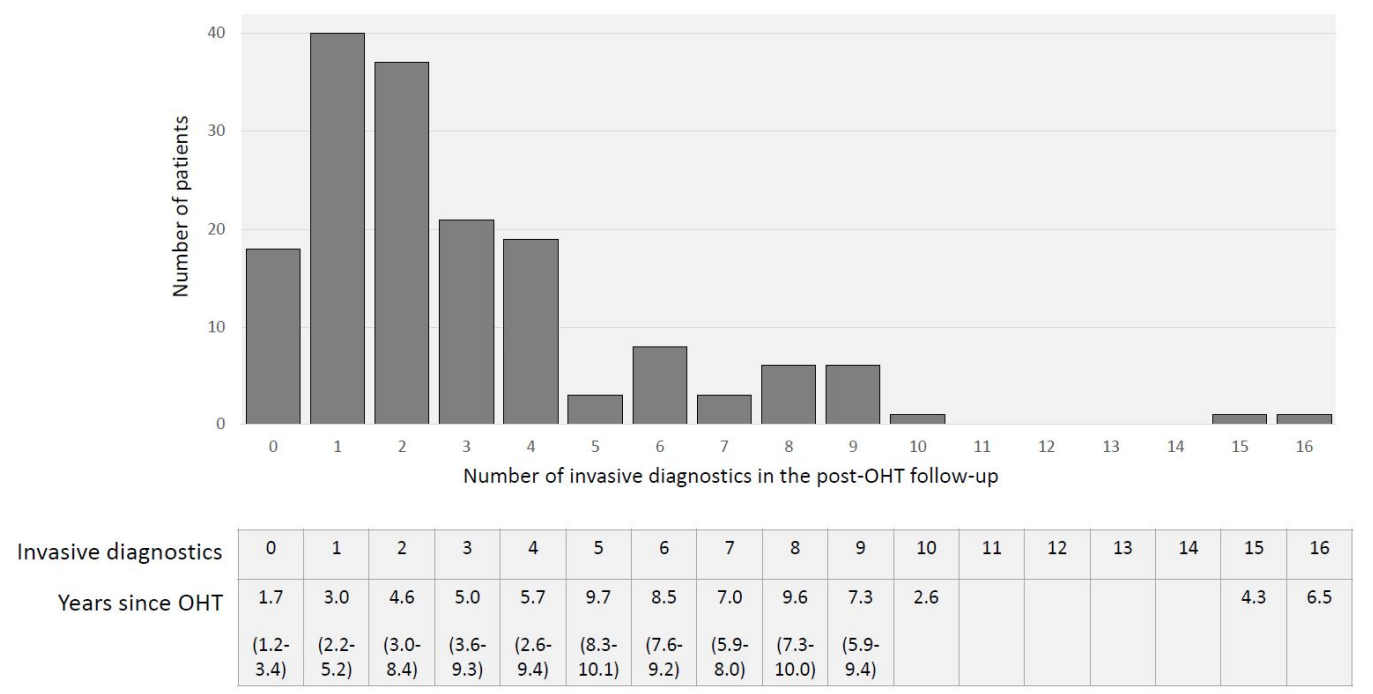

Figure 3. Total number of invasive diagnostics, including EMB and angiographies, during OHT follow-up and years since OHT (median (IQR)).

\subsection{Mortality, $A R$ and $C A V$}

Of all patients, $13.3 \%(n=22)$ died in a mean of $4.1( \pm 2.4)$ years after OHT. Figure 4 presents the survival rates of patients who survived the first post-transplant year. Causes of death were graft failure due to AR and CAV in $6(27.3 \%)$ and $4(18.2 \%)$ patients, respectively. Five $(22.7 \%)$ patients died due to an infection (necrotizing pancreatitis, mediastinitis, intracranial abscess, sepsis of other origins) and $2(9.1 \%)$ patients due to lung cancer. In 4 $(18.2 \%)$ patients, the cause of death was unknown.

A

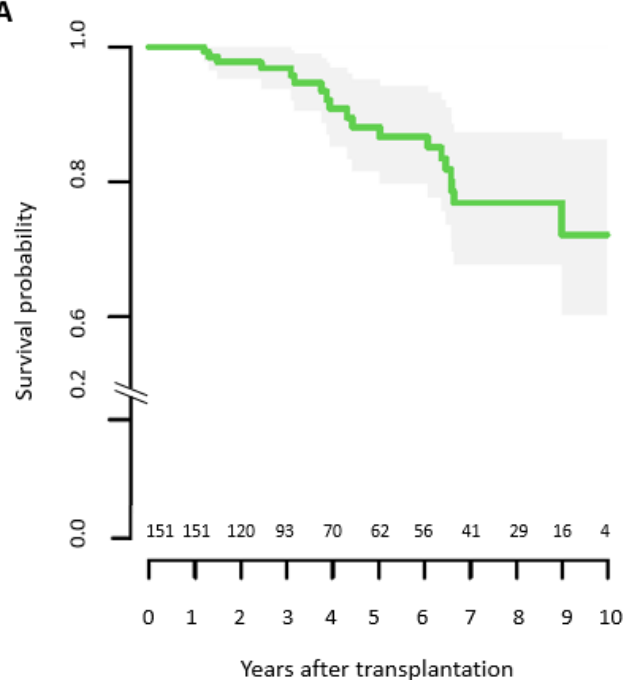

B

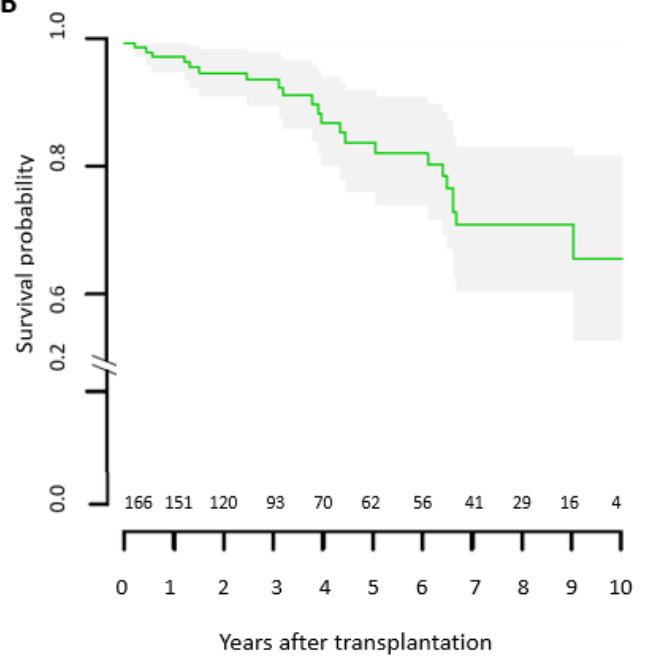

Figure 4. (A) Survival after OHT conditional on surviving to 1 year; (B) survival of study population.

In total, 170 episodes of AR (detected in 480 (34.5\%) invasive procedures) occurred post OHT follow-up. Of these ARs, $84(49.4 \%)$ were classified as mild ACR ISHLT1R, $13(7.6 \%)$ as moderate ACR ISHLT2R, and $8(4.7 \%)$ as severe ACR ISHLT3R; $65(38.2 \%)$ were caused by AMR. In 29 cardiac catheterizations, CAV was diagnosed: $5(17.2 \%)$ cases showed mild ISHLT CAV1, 4 (13.8\%) cases moderate ISHLT CAV2, and 20 (69.0\%) cases severe 
ISHLT CAV3. Of the 4 ISHLT CAV2 cases, 2 were progressions of a previously known CAV, and of the 20 ISHLT CAV3 cases, 8 were progressions of a previously known CAV.

\subsection{Sm Course after OHT}

Individual Sm values remained stable from discharge after OHT over the follow-up period. Radial and longitudinal Sm were $11.5 \pm 2.2$ and $10.9 \pm 2.1 \mathrm{~cm} / \mathrm{s}$, respectively (Figure 5).
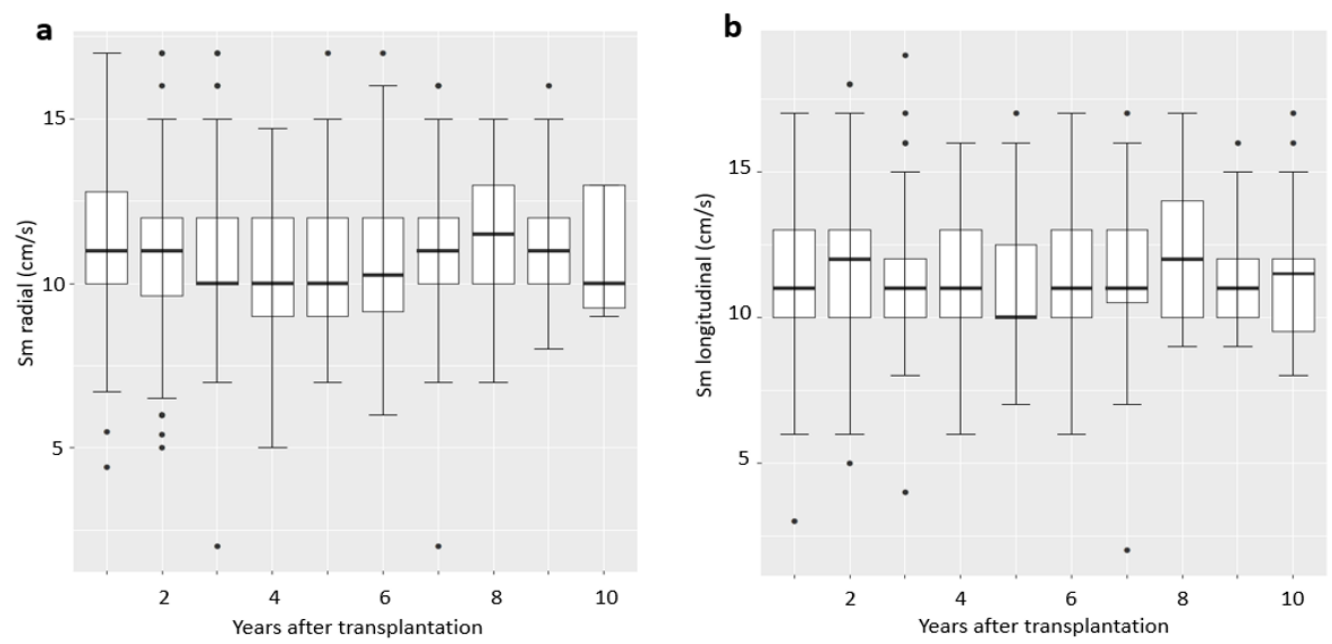

Figure 5. Course of (a) radial and (b) longitudinal Sm from discharge after OHT.

\subsection{Predictive Value of $S m$}

Patients with mild ACR ISHLT 1R or AR caused by AMR and ISHLT CAV3 showed intraindividual significant reductions in radial and longitudinal $\mathrm{Sm}$ with a decrease from $1.7 \pm 1.8 \mathrm{~cm} / \mathrm{s}$ and $2.0 \pm 1.6 \mathrm{~cm} / \mathrm{s}$, CI 1.32-2.08, $p<0.001$ and CI 1.66-2.34, $p<0.001$, respectively in ACR ISHLT 1R; $1.6 \pm 1.9 \mathrm{~cm} / \mathrm{s}$ and $1.8 \pm 2.0 \mathrm{~cm} / \mathrm{s}, 95 \%$ CI $0.77-0.243$, $p<0.001$ and CI 0.92-0.267, $p<0.001$, respectively in AMR; and $1.3 \pm 2.5 \mathrm{~cm} / \mathrm{s}$ and $1.4 \pm 2.8 \mathrm{~cm} / \mathrm{s}$, CI $0.23-2.43, p<0.017$ and CI $0.21-2.66, p<0.021$, respectively in ISHLT CAV3 (Tables 2 and 3).

\subsection{Prognostic Value of Sm}

In a time-varying covariate Cox regression model, lower radial or longitudinal Sm values at any time were associated with higher all-cause mortality per $\mathrm{cm} / \mathrm{s}$ decrease (hazard ratio (HR) 0.77, CI 0.63-0.93, $p=0.008$; HR 0.7, CI 0.58-0.95, $p=0.016$; HR, respectively), as presented in Table 4 . A radial $\mathrm{Sm}$ of less than $9 \mathrm{~cm} / \mathrm{s}$ and a longitudinal Sm of less than $10 \mathrm{~cm} / \mathrm{s}$ were associated with an approximately threefold increased risk of mortality (HR 3.24, CI 1.2-8.76, $p=0.020$; HR 2.92, CI 1.19-7.18, $p=0.019$; HR, respectively).

Table 2. Sm and LV-EF in CAV and ACR.

\begin{tabular}{|c|c|c|c|c|c|c|c|c|c|c|}
\hline \multirow[t]{2}{*}{ CAV Grade } & \multicolumn{3}{|c|}{ ISHLT CAV1 $n=5$} & \multicolumn{3}{|c|}{ ISHLT CAV2 $n=4$} & \multicolumn{4}{|c|}{ ISHLT CAV3 $n=20$} \\
\hline & Pre & CAV1 & Change & Pre & CAV2 & Change & Pre & CAV3 & Change & $\begin{array}{c}(\mathrm{CI}) \\
p \text { value }\end{array}$ \\
\hline $\mathrm{Sm} \mathrm{rad} \mathrm{cm/s}$ & $\begin{array}{c}10.7 \\
( \pm 1.2)\end{array}$ & $\begin{array}{c}9.9 \\
( \pm 0.7)\end{array}$ & $\begin{array}{c}-0.8 \\
( \pm 1.69)\end{array}$ & $\begin{array}{c}11.0 \\
( \pm 2.2)\end{array}$ & $\begin{array}{c}10.3 \\
( \pm 1.5)\end{array}$ & $\begin{array}{c}0.8 \\
( \pm 2.2)\end{array}$ & $\begin{array}{c}10.5 \\
( \pm 1.9)\end{array}$ & $\begin{array}{c}9.3 \\
( \pm 2.9)\end{array}$ & $\begin{array}{c}1.3 \\
( \pm 2.5)\end{array}$ & $\begin{array}{c}(0.23-2.43) \\
0.017\end{array}$ \\
\hline Sm long $\mathrm{cm} / \mathrm{s}$ & $\begin{array}{c}11.0 \\
( \pm 1.4)\end{array}$ & $\begin{array}{c}9.2 \\
( \pm 0.7)\end{array}$ & $\begin{array}{c}-1.8 \\
( \pm 1.3)\end{array}$ & $\begin{array}{c}10.8 \\
( \pm 2.2)\end{array}$ & $\begin{array}{c}10.8 \\
( \pm 2.2)\end{array}$ & $\begin{array}{c}0 \\
( \pm 2.5)\end{array}$ & $\begin{array}{c}10.6 \\
( \pm 2.2)\end{array}$ & $\begin{array}{c}9.5 \\
( \pm 2.6)\end{array}$ & $\begin{array}{c}1.4 \\
( \pm 2.8)\end{array}$ & $\begin{array}{c}(0.21-2.66) \\
0.021\end{array}$ \\
\hline LV-EF \% & $\begin{array}{c}60.0 \\
( \pm 3.2)\end{array}$ & $\begin{array}{c}56.0 \\
( \pm 11.6)\end{array}$ & $\begin{array}{c}-4.0 \\
( \pm 8.6)\end{array}$ & $\begin{array}{c}58.8 \\
( \pm 4.1)\end{array}$ & $\begin{array}{c}55.5 \\
( \pm 3.5)\end{array}$ & $\begin{array}{l}-3.75 \\
( \pm 1.1)\end{array}$ & $\begin{array}{c}56.9 \\
( \pm 6.7)\end{array}$ & $\begin{array}{c}52.1 \\
( \pm 12.0)\end{array}$ & $\begin{array}{c}4.8 \\
( \pm 10.0)\end{array}$ & $\begin{array}{c}(0.42-9.18) \\
0.031\end{array}$ \\
\hline
\end{tabular}


Table 2. Cont

\begin{tabular}{|c|c|c|c|c|c|c|c|c|c|c|}
\hline \multirow[t]{3}{*}{ CAV Grade } & \multirow{2}{*}{\multicolumn{3}{|c|}{$\begin{array}{c}\text { ISHLT CAV1 } n=\mathbf{5} \\
\text { ACR grade }\end{array}$}} & \multicolumn{4}{|c|}{ ISHLT CAV2 $n=4$} & \multirow{2}{*}{\multicolumn{3}{|c|}{$\begin{array}{r}\text { ISHLT CAV3 } n=\mathbf{2 0} \\
\text { ISHLT 3R } n=8\end{array}$}} \\
\hline & & & & \multirow{2}{*}{$\begin{array}{c}\text { ISHLT } 1 \mathrm{R} n=84 \\
(\mathrm{CI}) \\
p \text { value }\end{array}$} & \multicolumn{3}{|c|}{ ISHLT $2 \mathrm{R} n=13$} & & & \\
\hline & pre & $1 \mathrm{R}$ & change & & pre & $2 \mathrm{R}$ & change & pre & $3 R$ & change \\
\hline $\mathrm{Sm} \mathrm{rad} \mathrm{cm/s}$ & $\begin{array}{c}11.3 \\
( \pm 2.0)\end{array}$ & $\begin{array}{c}9.6 \\
( \pm 2.0)\end{array}$ & $\begin{array}{c}-1.7 \\
( \pm 1.8)\end{array}$ & $\begin{array}{c}(1.32-2.08) \\
\quad<0.001\end{array}$ & $\begin{array}{c}11.3 \\
( \pm 1.7)\end{array}$ & $\begin{array}{c}9.1 \\
( \pm 2.4)\end{array}$ & $\begin{array}{c}-1.9 \\
( \pm 2.3)\end{array}$ & $\begin{array}{c}11.4 \\
( \pm 2.1)\end{array}$ & $\begin{array}{c}9.4 \\
( \pm 2.1)\end{array}$ & $\begin{array}{c}-2.6 \\
( \pm 3.0)\end{array}$ \\
\hline Sm long cm/s & $\begin{array}{c}11.8 \\
( \pm 1.7)\end{array}$ & $\begin{array}{c}10.0 \\
( \pm 2.4)\end{array}$ & $\begin{array}{c}-2.0 \\
( \pm 1.6)\end{array}$ & $\begin{array}{c}(1.66-2.34) \\
<0.001\end{array}$ & $\begin{array}{c}11.7 \\
( \pm 1.8)\end{array}$ & $\begin{array}{c}9.1 \\
( \pm 2.9)\end{array}$ & $\begin{array}{c}-2.3 \\
( \pm 2.4)\end{array}$ & $\begin{array}{c}11.9 \\
( \pm 1.8)\end{array}$ & $\begin{array}{c}9.1 \\
( \pm 1.8)\end{array}$ & $\begin{array}{c}-3.4 \\
( \pm 1.9)\end{array}$ \\
\hline LV-EF \% & $\begin{array}{c}62.6 \\
( \pm 5.8)\end{array}$ & $\begin{array}{c}57.9 \\
( \pm 8.8)\end{array}$ & $\begin{array}{c}-5.3 \\
( \pm 6.8)\end{array}$ & $\begin{array}{c}(3.85-6.75) \\
<0.001\end{array}$ & $\begin{array}{c}60.4 \\
( \pm 4.0)\end{array}$ & $\begin{array}{c}53.8 \\
( \pm 12.7)\end{array}$ & $\begin{array}{c}-7.1 \\
( \pm 16.2)\end{array}$ & $\begin{array}{c}65.0 \\
( \pm 3.5)\end{array}$ & $\begin{array}{c}54.4 \\
( \pm 14.5)\end{array}$ & $\begin{array}{c}-10.6 \\
( \pm 13.3)\end{array}$ \\
\hline
\end{tabular}

ACR, acute cellular rejection; CAV, cardiac allograft vasculopathy; CI, confidence interval; ISHLT, International Society for Heart and Lung Transplantation; long, longitudinal; LV-EF, left ventricular rejection fraction; rad radial; Sm, systolic wall motion peak velocity.

Table 3. Sm and LV-EF in AMR.

\begin{tabular}{ccccc}
\hline \multicolumn{5}{c}{ ISHLT AMR $n=65$} \\
\hline Pre & AMR & Change (\%) & (CI) $p$ Value \\
\hline Sm rad cm/s & $11.7( \pm 1.9)$ & $10.1( \pm 2.1)$ & $-1.6( \pm 1.9)$ & $(0.77-2.43)<0.001$ \\
\hline LV-EF \% & $11.9( \pm 1.5)$ & $10.3( \pm 2.0)$ & $-1.8( \pm 2.0)$ & $(0.92-2.67)<0.001$ \\
\hline
\end{tabular}

AMR, antibody-mediated rejection; ISHLT, International Society For Heart And Lung Transplantation; long, longitudinal; LV-EF, left ventricular rejection fraction; rad radial; Sm, systolic wall motion peak velocity.

Table 4. Sm as a predictor of mortality.

\begin{tabular}{cccc}
\hline & Hazard Ratio & $\mathbf{9 5 \%}$ CI & $p$ Value \\
\hline Sm long, cm/s & 0.74 & $0.58-0.95$ & 0.016 \\
\hline Sm rad, cm/s & 0.77 & $0.63-0.93$ & 0.008 \\
\hline IVSd per mm & 0.94 & $0.72-1.21$ & 0.607 \\
\hline LV-EF, \% & 1.0 & $0.95-1.05$ & 0.968 \\
\hline Sm long $\geq 10 \mathrm{~cm} / \mathrm{s}$ & 0.34 & $0.14-0.84$ & 0.019 \\
\hline Sm long $<10 \mathrm{~cm} / \mathrm{s}$ & 2.92 & $1.19-7.18$ & 0.019 \\
\hline Sm rad $\geq 9 \mathrm{~cm} / \mathrm{s}$ & 0.31 & $0.11-0.83$ & 0.020 \\
\hline Sm rad $<9 \mathrm{~cm} / \mathrm{s}$ & 3.24 & $1.2-8.76$ & 0.020 \\
\hline
\end{tabular}

CI, confidence interval; IVSd, interventricular septum enddiastolic; Sm, systolic wall motion peak velocity.

\section{Discussion}

Our analysis shows that the PW-TDI-derived systolic wall motion of the posterobasal segment of the left ventricle remains stable for at least 10 years after OHT. A decrease in Sm may indicate AR or CAV and is a predictor of mortality.

After Dandel et al. described the high diagnostic value of Sm measurements for predicting ACR and CAV, and its usefulness for the scheduling of invasive diagnostics in a prospective clinical trial in 2001, our institutional routine post-transplant care was adapted with a shift from routine surveillance to a clinical-echocardiographic navigation of EMB and angiography [12-14]. The present work represents a long-term follow-up of our experiences following this novel approach. In our recent analysis, low-grade ACR and high-grade CAV were accompanied by a significant reduction in Sm. This complements previously published work, where medium- and high-grade ACR (ISHLT $\geq 2 \mathrm{R}$ ), and lowgrade or angiographically invisible CAV were reliably indicated by a Sm decrease [12-14]. 
Additionally, we first describe here a significant $\mathrm{Sm}$ reduction in patients with AR caused by AMR (which was defined by the ISHLT in 2005) [7].

Moreover, in our analysis, we observed a stable long-term Sm course, which supports the usefulness of Sm surveillance over the post-OHT period. A one-time detection of radial or longitudinal $S \mathrm{Sm}$ of $<9 \mathrm{~cm} / \mathrm{s}$ or $<10 \mathrm{~cm} / \mathrm{s}$, respectively, was associated with a threefold increased risk of all-cause mortality, underlining the prognostic value of the Sm measurements.

Our patients received 0.75 EMBs and/or angiographies per patient post OHT year. Patients who had been transplanted for at least 5 years $(n=77$, mean $8.4 \pm 1.7$ years post OHT) had a median of 3 (IQR 2-6) invasive diagnostic procedures during follow-up, which is an extremely low frequency compared to the guideline recommendations or to symptomtriggered biopsy protocols reported in the literature [4,15-17]. In $170(35.4 \%)$ invasive procedures, EMBs or angiographies confirmed suspected $\mathrm{AR}$ or $\mathrm{CAV}$, so that Sm-navigated invasive diagnostics can be referred to as a high-yield screening modality for post-OHT AR or CAV [18].

Our institutional conditional survival rates were comparable to the rates reported for de novo or post long-term circulatory support transplant recipients in large American databases or European transplant centers within the Eurotransplant or Scandiatransplant region [19-22].

LV-EF and strain analysis, as other echocardiographic parameters for LV myocardial function, have been described as predictors of graft failure after OHT. LV-EF decreases in advanced AR. But several pitfalls limit the accuracy of LV-EF measurements: (i) the endocardium border must be clearly visible in every segment of the apical 4- and 2-chamber view, (ii) apical foreshortening due to transducer angulation or atypical views leads to measurement errors, and (iii) the eye-balling technique for LV-EF estimation in cases of insufficient imaging quality is highly interobserver-dependent [23]. Due to these limitations, small changes in LV-EF, as reported for our patients with ISHLT1R AR, are not reliably detectable. Speckle-tracking-based global longitudinal strain (GLS) analyses and segmental longitudinal strain reliably indicate AR and CAV in OHT cohorts. Compared to TDI, this method is less angle- and interobserver-dependent. However, a major disadvantage is that high imaging quality is required; therefore, GLS is only applicable in selected patients [24-26].

Overall, we postulate clinical-Sm-triggered OHT follow-up care as a safe, noninvasive, reliable, and potentially cost-effective strategy for heart transplant recipients.

\section{Limitations}

This analysis has certain limitations: The investigation was performed retrospectively in a single center and the samples of high-grade ACR and low-grade CAV were too small to perform statistical testing. Furthermore, we examined the role of echocardiographic surveillance in detecting histological rejection; the occurrence of symptoms and the need for treatment were not taken into account.

Author Contributions: Conceptualization, I.A.J., J.K. and F.S.; methodology, I.A.J., M.G. (Meryem Guelfirat), J.K. and F.S.; software: I.A.J., M.G. (Meryem Guelfirat), L.L., A.U. and M.G. (Maren Godde); validation, I.A.J., N.M., F.H., C.K., V.F., J.K. and F.S.; formal analysis, I.A.J., M.G. (Meryem Guelfirat), J.K. and F.S.; investigation, I.A.J., M.G. (Meryem Guelfirat), C.K., V.F., J.K. and F.S.; resources, all authors; data curation, I.A.J., M.G. (Meryem Guelfirat), L.L., A.U., M.G. (Maren Godde) and L.K.F.; writing-original draft preparation, I.A.J.; writing-review and editing, all authors; visualization, I.A.J.; supervision, P.S., C.K., V.F., J.K. and F.S.; project administration, I.A.J., J.K. and F.S. All authors have read and agreed to the published version of the manuscript.

Funding: This research received no external funding.

Institutional Review Board Statement: The study was conducted according to the guidelines of the Declaration of Helsinki, and approved by the Ethics Committee of Charité Universitätsmedizin Berlin (EA2/169/19; approved in 10/2019). 
Informed Consent Statement: Patient consent was waived due to the retrospective nature of this analysis.

Acknowledgments: The authors are pleased to acknowledge Julia Stein, who provided statistical data analysis.

Conflicts of Interest: N.M. is on the advisory board of Siemens. P.S. has received consultancy and lecture honoraria from Amgen, Novartis, Sanofi-Aventis, Bristol-Myers Squibb/Pfizer, DaiichiSankyo, Bayer, Boehringer Ingelheim, BerlinChemie, B. Braun, Medtronic, AstraZeneca; and editor honoraria from Springer Nature. V.F. has relevant (institutional) financial activities outside the submitted work with the following commercial entities: Medtronic GmbH, Biotronik SE \& Co., Abbott GmbH \& Co. KG, Boston Scientific, Abiomed, Edwards Lifesciences, Berlin Heart, Novartis Pharma GmbH, JOTEC/CryoLife GmbH, and Zurich Heart. F.S. reports other from Novartis, other from Abbott, nonfinancial support from Medtronic, other from Orion Pharma, other from Astra Zeneca, outside the submitted work. The other authors declare that there are no conflicts of interest. The funders had no role in the design of the study; in the collection, analyses, or interpretation of data; in the writing of the manuscript, or in the decision to publish the results.

\section{References}

1. Chambers, D.C.; Cherikh, W.S.; Chambers, D.C.; Harhay, M.O.; Hyes, D.J.; Hsish, E.; Meiser, B.; Potena, L.; Robinson, A.; Rossano, J.W.; et al. The International Thoracic-Organ-Transplant-Registry of the International Society for Heart and Lung Transplantation: Thirty-sixth adult heart transplantation report-2019; focus theme: Donor and recipient size match. J. Heart Lung Transplant. 2019, 38, 1056-1066. [CrossRef] [PubMed]

2. $\quad$ Lund, L.H.; Khush, K.K.; Cherikh, W.S.; Goldfarb, S.; Kucheryavaya, A.Y.; Levvey, B.J.; Meiser, B.; Rossano, J.W.; Chambers, D.C.; Yusen, R.D.; et al. The Registry of the International Society for Heart and Lung Transplantation: Thirty-fourth Adult Heart Transplantation Report-2017; Focus theme: Allograft ischemic time. J. Heart Lung Transplant. 2017, 36, 1037-1046. [CrossRef] [PubMed]

3. Chih, S.; Chong, A.Y.; Mielniczuk, L.M.; Bhatt, D.L.; Beanlands, R.S. Allograft vasculopathy: The Achilles' heel of heart transplantation. J. Am. Coll. Cardiol. 2016, 68, 80-91. [CrossRef] [PubMed]

4. Constanzo, M.R.; Dipchand, A.; Starling, R.; Anderson, A.; Chan, M.; Desai, S.; Fedson, S.; Fisher, P.; Gonzales-Stawinski, G.; Martinelli, L.; et al. The international society of heart and lung transplantation guidelines for the care of heart transplant recipients. J. Heart Lung Transplant. 2010, 29, 914-956. [CrossRef] [PubMed]

5. From, A.M.; Maleszewski, J.J.; Rihal, C.S. Current status of endomyocardial biopsy. Mayo Clin. Proc. 2011, 86, 1095-1102. [CrossRef] [PubMed]

6. Wallace, C.K.; Koerner, M.; THohan, V.; Torre-Amione, G. Frequent surveillance biopsies do not improve survival following heart transplantation. J. Heart Lung Transplant. 2004, 23, S74. [CrossRef]

7. Stewart, S.; Winters, G.L.; Fishbein, M.C.; Tazelaar, H.D.; Kobashigawa, J.; Abrams, J.; Andersen, C.B.; Angelini, A.; Berry, G.J.; Burke, M.M.; et al. Revision of the 1990 working formulation for the standardization of nomenclature in the diagnosis of heart rejection. J. Heart Lung Transplant. 2005, 24, 1710. [CrossRef]

8. Berry, G.J.; Burke, M.M.; Andersen, C.; Bruneval, P.; Fedrigo, M.; Fishbein, M.C.; Goddard, M.; Hammond, E.H.; Leone, O.; Marboe, C.; et al. The 2013 International Society for Heart and Lung Transplantation working formulation for the standardization of nomenclature in the pathologic diagnosis of antibody-mediated rejection in heart transplantation. J. Heart Lung Transplant. 2013, 32, 1147-1162. [CrossRef]

9. Tsutsui, H.; Ziada, K.M.; Schoenhagen, P.; Iyisoy, A.; Magyar, W.A.; Crowe, T.D.; Klingensmith, J.D.; Vince, D.G.; Rincon, G.; Hobbs, R.E.; et al. Lumen loss in transplant coronary artery disease is a biphasic process involving early intimal thickening and late constrictive remodeling: Results from a 5-year serial intravascular ultrasound study. Circulation 2001, 104, 653-657. [CrossRef]

10. Hirohata, A.; Nakamura, M.; Waseda, K.; Honda, Y.; Lee, D.P.; Vagelos, R.H.; Hunt, S.A.; Valantine, H.A.; Yock, P.G.; Fitzgerald, P.J.; et al. Changes in coronary anatomy and physiology after heart transplantation. Am. J. Cardiol. 2007, 99, 1603-1607. [CrossRef]

11. Mehra, M.R.; Crespo-Leiro, M.G.; Dipchand, A.; Ensminger, S.M.; Hiemann, N.E.; Kobashigawa, J.A.; Madsen, J.; Parameshwar, J.; Starling, R.C.; Uber, P.A. International Society for Heart and Lung Transplantationworking formulation of a standardized nomenclature forcardiac allograft vasculopathy-2010. J. Heart Lung Transplant. 2010, 29, 717-727. [CrossRef]

12. Dandel, M.; Hummel, M.; Mueller, J.; Wellnhofer, E.; Meyer, R.; Solowjowa, N.; Ewert, R.; Hetzer, R. Reliability of tissue Doppler wall motion monitoring after heart transplantation for replacement of invasve routine screenings by optimally timed cardiac biopsies and catheterizations. Circulation 2001, 104, I184-I191. [CrossRef] [PubMed]

13. Dandel, M.; Hummel, M.; Mueller, R.; Ewert, R.; Hetzer, R. Wall motion assessment by tissue Doppler imaging after heart transplantation: Timing of endomyocardial biopsies and facilitation of therapeutic decisions during acute cardiac rejection. J. Heart Lung Transplant. 2001, 20, 213. [CrossRef] 
14. Dandel, M.; Hummel, M.; Wellnhofer, E.; Mueller, J.; Ewert, R.; Hetzer, R. Usefulness of post-transplant wall motion analysis by tissue Doppler imaging in patients with cardiac allograft vasculopathy: Evaluation of functional severity and timing of follow-up cardiac catheterizations. J. Heart Lung Transplant. 2001, 20, 151. [CrossRef]

15. Sinphurmsukskul, S.; Ariyachaipanich, A.; Siwamogsatham, S.; Thammanatsakul, K.; Puwanant, S.; Benjacholamas, V.; Ongcharit, P. Endomyocardial biopsy and prevalence of acute cellular rejection in heart transplantation. Transplant. Proc. 2021, 53, 318-323. [CrossRef] [PubMed]

16. Weckbach, L.; Maurer, U.; Schramm, R.; Huber, B.C.; Lackermair, K.; Weiss, M.; Meiser, B.; Hagl, C.; Massberg, S.; Eifert, S.; et al. Lower frequency routine surveillance endomyocardial biopsies after heart transplantation. PLoS ONE 2017, 12, e0182880. [CrossRef]

17. Stehlik, J.; Starling, R.C.; Movsesian, M.A.; Fang, J.C.; Brown, R.N.; Hess, M.L.; Lewis, N.P.; Kirklin, J.K.; Cardiac Transplant Database Group. Utility of long-term surveillance endomyocardial biopsy: A multi-institutional analysis. J. Heart Lung Transplant. 2006, 25, 1402-1409. [CrossRef]

18. Orrego, C.M.; Cordero-Reyes, A.M.; Estep, J.D.; Loebe, M.; Torre-Amione, G. Usefulness of routine surveillance endomyocardial biopsy 6 months after heart transplantation. J. Heart Lung Transplant. 2012, 31, 845-849. [CrossRef]

19. Suarez-Pierre, A.; Lui, C.; Zhou, X.; Fraser, C.D.; Ferrigno, A.S.; Etchill, E.; Giuliano, K.; Higgins, R.S.; Choi, C.W.; Kilic, A. Conditional survival in heart transplantation: An organ procurement and transplantation network database analysis. Ann. Thorac. Surg. 2020, 110, 1339-1347. [CrossRef]

20. Suarez-Pierre, A.; Zhou, X.; Fraser, C.D.; Grimm, J.C.; Crawford, T.C.; Lui, C.; Valero, V.; Choi, C.W.; Higgins, R.S.; Kilic, A. Survival and functional status after bridge-to-transplant with left ventricular assist device. ASAIO J. 2019, 65, 661-667. [CrossRef]

21. Sammani, A.; Wind, A.M.; Kirkels, J.H.; Kloepping, C.; Buijsrogge, M.P.; Ramjakhan, F.Z.; Asselbergs, F.W.; de Jonge, N. Thirty years of heart transplantation at the Univercity Medial Centre Utrecht. Neth. Heart J. 2017, 25, 516-523. [CrossRef] [PubMed]

22. Dellgren, G.; Geiran, O.; Lemstroem, K.; Gustafsson, F.; Eiskjaer, H.; Koul, B.; Hagermann, I.; Selimovic, N. Nordic Thoracic Transplant Study Group. Three decades of heart transplantation in Scandinavia:long-term follow-up. Eur. J. Heart Fail. 2013, 15, 308-315. [CrossRef]

23. Badano, L.P.; Miglioranza, M.H.; Edvardsen, T.; Colafranceschi, A.S.; Muraru, D.; Bacal, F.; Nieman, K.; Zoppellaro, G.; Marcondes Braga, F.G.; Binder, T.; et al. European association of cardiovascular imaging/cardiovascular imaging department of the Brazilian society of cardiology recommendations for the use of cardiac imaging to assess and follow patients after heart transplantation. Eur. Heart J. Cardiovasc. Imaging 2015, 16, 919-948. [CrossRef] [PubMed]

24. Ghali, M.G.Z.; Stewart, R.; Ghali, G.Z.; Blitzer, W. Two dimensional speckle tracking echocardiography detects cardiac allograft stage III vasculopathy in recipients of heart transplants with preserved systolic function. Acta Cardiol. 2020, 31, 1-11. [CrossRef]

25. Clemmensen, T.S.; Logstrup, B.B.; Eiskjaer, H.; Poulsen, S.H. Evaluation of longitudinal myocardial deformation by 2-dimentional speckle tracking echocardiography in heart transplant recipients: Relation to coronary artery vasculopathy. J. Heart Lung Transplant. 2015, 34, 195-203. [CrossRef] [PubMed]

26. Pichler, P.; Binder, T.; Höfer, P.; Bergler-Klein, J. Two-dimensional speckle tracking echocardiography in heart transplant patients: Three-year Follow-up of deformation parameters and ejection fraction derived from transthoracic echocardiography. Eur. Heart J. Cardiovasc. Imaging 2012, 13, 181-186. [CrossRef] 